http://dx.doi.org/10.35381/racji.v5i8.659

\title{
Derecho de petición, derecho a información y a recibir servicios públicos de calidad
}

\section{Right to petition, right to information and to receive quality public services}

\author{
Edison Manuel Pozo-Calderón \\ Escuela Superior Politécnica de Chimborazo, Riobamba \\ emanuelpozoc@hotmail.com \\ Ecuador \\ https://orcid.org/0000-0002-0909-693X \\ Julio César Garate-Amoroso \\ Universidad Católica de Cuenca, Cuenca \\ gcgaratea@ucacea.edu.ec \\ Ecuador \\ https://orcid.org/0000-0003-0947-9620 \\ Pedro Rolando Cusi-Chambi \\ Universidad Andina Simón Bolívar, Sede Central Sucre \\ rolandocusi.net@gmail.com \\ Ecuador \\ https://orcid.org/0000-0002-8958-799X \\ Alberto Quispe-Gabincha \\ Universidad Andina Simón Bolívar, Sede Central Sucre \\ quispegabincha@gmail.com \\ Ecuador \\ https://orcid.org/0000-0001-6705-0158
}

Recibido: 18 de noviembre de 2019

Aprobado: 19 de diciembre de 2019

\section{RESUMEN}

La investigación tuvo como objetivo principal elaborar un proyecto de Ley Reformatoria a la Ley Orgánica de Garantías Jurisdiccionales y Control Constitucional, para garantizar el Derecho de Petición. Se fundamentó metodológicamente desde un trabajo descriptivo con diseño de campo no experimental, la muestra poblacional, se trabajó con 97 registrados en el Foro de abogados de la provincia de El Oro, Ecuador. Se vulneran 
múltiples derechos constitucionales entre estos el libre acceso a la información y a recibir servicios públicos de calidad, entre otros. Es por esta razón, que es sumamente necesario establecer un marco legal y un procedimiento rápido moderno y sencillo para que las instituciones reciban y atiendan nuestras peticiones sin la exigencia de formalidades innecesarias. El Derecho Constitucional de Petición debe cumplir su función y ser una herramienta que en forma ágil, rápida y sencilla, permita la vinculación de la ciudadanía y la Administración Pública o Privada.

Descriptores: Libertad de expresión; derechos civiles; derecho constitucional; servicios.

\section{ABSTRACT}

The main objective of the investigation was to prepare a draft Reform Law to the Organic Law of Jurisdictional Guarantees and Constitutional Control, to guarantee the Right of Petition. It was based methodologically from a descriptive work with non-experimental field design, the population sample, we worked with 97 registered in the Lawyers Forum of the province of El Oro, Ecuador. Multiple constitutional rights are violated, including free access to information and receiving quality public services, among others. It is for this reason that it is extremely necessary to establish a legal framework and a modern and simple rapid procedure for institutions to receive and respond to our requests without the need for unnecessary formalities. The Constitutional Law of Petition must fulfill its function and be a tool that in an agile, fast and simple way, allows the linking of citizenship and Public or Private Administration.

Descriptors: Freedom of expression; civil and political rights; constitutional law; services.

\section{INTRODUCCIÓN}

El derecho Constitucional de Petición es un derecho primordial estipulado en el artículo 66 numeral 23, de la Constitución de la República del Ecuador (2008), como aval constitucional, su objetivo es el acceso directo del ciudadano a las instituciones del Estado, para presentar solicitudes ante las autoridades de la administración pública o ante ciertos particulares, procurando lograr de ellos una rápida resolución sobre lo solicitado, es un derecho elemental, siendo pieza importante de los mecanismos de participación y control ciudadano. Pero hace falta establecer un procedimiento, los mecanismos para su utilización eficiente, eficaz, para beneficio de todos los ciudadanos. 
Sin embargo, el Derecho de Petición ha evolucionado mundialmente, mientras que en Ecuador ni siquiera existe un pronunciamiento jurisprudencial obligatorio de la Corte Constitucional sobre este, cosa que si ha ocurrido en otros países como Colombia, por ejemplo donde la Corte Constitucional ha alzado su voz, ha dictado textos aditivos que han aclarado el procedimiento y los casos en los que procede, en el caso de Colombia por ejemplo, donde existe la Ley 1755 que Regula el Derecho de Petición.

En este sentido, el derecho de petición en la República del Ecuador, actualmente no está cumpliendo su función, que es la de permitir el acceso eficaz y eficiente de todos los ciudadanos tanto nacionales como extranjero a las instituciones del estado, para exigir la prestación de servicios, presentar consultas, quejas, solicitar información, entre otras cosas.

Es por ello, que al no existir un adecuado procedimiento y un mecanismo que regule el derecho de petición establecido en el artículo 66 numeral 23 de la Constitución de la República del Ecuador, y articulo 32 del Reciente Código Orgánico Administrativo aprobado por la Asamblea Nacional del Ecuador, publicado en el Registro Oficial Suplemento 31 de fecha 7 de julio del 2017, que entró en plena vigencia el día 8 de julio del año 2018, la ciudadanía en general no puede acceder directamente y en forma eficiente y eficaz mediante una petición escrita, verbal o por medios electrónicos a las Instituciones del Estado a ejercer sus derechos.

No obstante, en Ecuador se ha desplegado en forma variada el empleo del Derecho de Petición, en las diversas instituciones del Estado, sin poderse establecer hasta la fecha un criterio uniforme, más allá de las escuetas normas sobre el tema en la Constitución de la República del Ecuador, Ley de Garantías Constitucionales, Control Constitucional y el reciente Código Orgánico Administrativo, ocasionando vacíos legales, procedimentales, violación de derechos constitucionales, generando la ampliación de una brecha entre las Instituciones, así como ciudadanía en general. Por lo que es un grave problema legal y de procedimiento que debe regularse ya que no le permite a la 
ciudadanía acceder directamente a la información o los servicios que deben brindar las instituciones públicas.

Considerando que la Constitución de la República del Ecuador (2008) establece y garantiza el Derecho de Petición en su artículo 66 numeral 23, este no se encuentra adecuadamente regulado en la Ley Orgánica de Garantías Jurisdiccionales y Control Constitucional, donde debería constar y debería establecerse un procedimiento. Esto causa inconvenientes entre los ciudadanos y la Administración Publica, que por lo general exigen formalidades innecesarias, no reciben, no contestan, no responden o no motivan sus respuestas a la ciudadanía cuando ha presentado una Petición.

Por consiguiente, esto quebranta el derecho de Petición, Derecho a la Información y acceso a la información y derecho a recibir bienes y servicio de calidad. Por esta razón se justifica plenamente la elaboración de un proyecto de Ley Reformatoria a Ley Orgánica de Garantías Jurisdiccionales y Control Constitucional, para garantizar el Derecho de Petición, el libre acceso a la información y a recibir servicios públicos de calidad con eficacia y eficiencia (Aldana Zavala \& Isea, 2018a).. Por lo que es un grave problema legal, de procedimiento que debe regularse ya que no les permite a los ciudadanos acceder de manera efectiva, directa a la información o los servicios que deben ofrecer los organismos públicos, lo fundamental que se regulará es lo siguiente:

1. Cualquier solicitud realizada a un servidor público en ejercicio de sus funciones, se entiende que es competencia del derecho constitucional de petición, a pesar de que este no se haya exhortado expresamente.

2. El tiempo estipulado para dar solución a un derecho de petición es de 15 días. Si se refiere a una consulta el término es de 30 días. Para requerimientos de información y documentos, el tiempo es de 10 días.

3. Es permitido el libre ejercicio ante entidades privadas que realicen funciones de beneficio público, o concesiones.

4. Salvo disposición en contrario, no es de carácter obligatorio acatar los dictámenes emitidos por una autoridad estatal. 
5. En ejercicio del derecho de petición se podrá pedir: el ejercicio de un derecho, la intervención de una entidad o funcionario, la resolución de una situación jurídica, la prestación de un servicio, requerir información, consultar, examinar y requerir copias de documentos, formular consultas, quejas, denuncias y reclamos e interponer recursos.

6. El ejercicio del derecho de petición es gratis. Puede efectuarse sin necesidad de representación a través de un abogado.

7. La petición podrá presentase verbalmente, por escrito o a través de cualquier medio apto para la comunicación. Para el ejercicio de la petición verbal cada entidad dispondrá de una oficina y la misma será normada por el gobierno nacional.

8. Las autoridades, por ningún motivo, pueden negarse a la permanencia o aceptación de peticiones corteses, aunque pueda considerarse incompleta la petición se aceptará y se exigirán los documentos que se considere necesarios para emitir una respuesta al peticionario.

9. Las peticiones que involucren la atención de un derecho fundamental tendrán prioridad.

\section{Objetivos de la investigación Objetivo General}

Elaborar un proyecto de Ley Reformatoria a la Ley Orgánica de Garantías Jurisdiccionales y Control Constitucional, para garantizar el Derecho de Petición, el libre acceso a la información y a recibir servicios públicos de calidad con eficacia y eficiencia.

\section{Objetivos específicos}

- Fundamentar Jurídica y doctrinariamente el Derecho constitucional de Petición, el Derecho a la información y a recibir servicios públicos de calidad.

- Determinar que la Normativa constitucional que establece el Derecho de Petición vulnera el libre acceso a la información y el derecho a recibir servicio públicos de calidad. 
- Establecer los elementos para la elaboración del proyecto de Ley Reformatoria a la Ley Orgánica de Garantías Jurisdiccionales y Control Constitucional, sobre el Derecho de Petición que garantice el libre acceso a la información y el derecho a recibir servicio públicos de calidad con eficacia y eficiencia.

\section{Justificación de la investigación}

Es de suma importancia atender los vacíos legales referente al Derecho Constitucional de Petición que existen en la Ley Orgánica de Garantías Jurisdiccionales y Control Constitucional, por cuanto esto está vulnerando Derechos Constitucionales como el derecho de Petición, Derecho a la Información y acceso a la información, derecho a recibir bienes y servicios de calidad (Aldana Zavala \& Isea, 2018b). Toda la ciudadanía se ve afectada, debido que no existe una regulación, no existe un procedimiento y los vacíos legales de la actual legislación no permiten que se ejerza el derecho de petición en forma oral o por cualquier medio electrónico o tecnológico.

Aunque la Constitución de la República del Ecuador (2008), establece y garantiza el Derecho De Petición en su artículo 66 numeral 23, este no se encuentra adecuadamente regulado en la Ley Orgánica de Garantías Jurisdiccionales y Control Constitucional, donde debería constar y debería establecerse un procedimiento. Esto causa inconvenientes entre los ciudadanos y la Administración Publica, que por lo general exigen formalidades innecesarias, no reciben, no contestan, no responden o no motivan sus respuestas a la ciudadanía cuando ha presentado una Petición. Esto vulnera el derecho de Petición, Derecho a la Información, derecho a recibir bienes y servicio de calidad (Pérez Carrillo, 2019). Por esta razón se Justifica Plenamente la Elaboración de un proyecto de Ley Reformatoria a Ley Orgánica de Garantías Jurisdiccionales y Control Constitucional, para garantizar el Derecho de Petición, el libre acceso a la información y a recibir servicios públicos de calidad con eficacia y eficiencia. 


\section{MÉTODO}

El método empleado en la investigación fue el hipotético - deductivo, mediante una investigación de tipo descriptiva con diseño de campo no experimental (Hernández, Fernández y Baptista, 2014), lo cual permitió una aproximación al tema a investigar y la relación objetiva entre las variables. En cuanto a la muestra poblacional, se trabajó con 97 registrados en el Foro de abogados de la provincia de El Oro, Ecuador, a quienes se les aplicó un cuestionario tipo dicotómico de 10 preguntas, mediante la técnica de la encuesta.

El cuestionario aplicado fue validado por el juicio de tres expertos, ejecutándose una prueba de confiabilidad de Kuder de Richardson 20, mediante una prueba piloto desarrollada en 10 personas con características similares a la muestra, pero que no pertenecieron a la misma, obteniéndose un coeficiente de 8,86 catalogándose como confiable para su aplicación, de ese modo, se procedió a calcular los resultados del instrumento final en función de la estadística descriptiva, mediante distribución porcentual.

\section{RESULTADOS}

Tras realizar el análisis correspondiente a las respuestas de los expertos, se presentan los resultados que arrojó en cada pregunta:

De la pregunta uno, se infiere que el $94 \%$ de los encuestados conocen que el Derecho Constitucional de Petición no se encuentra normado en la Ley Orgánica de Garantías Jurisdiccionales y control Constitucional, mientras que un $6 \%$ manifiesta lo contrario.

De la pregunta dos, se determina que el $95 \%$ de los encuestados consideran que la normativa que actualmente regula el derecho de petición vulnera el libre acceso a la información pública, mientras que el $5 \%$ manifiesta lo contrario.

De la pregunta tres, se determina que el $98 \%$ de los encuestados consideran que la normativa que garantiza el derecho de petición vulnera el derecho a recibir servicios públicos de calidad, mientras que el $2 \%$ de los encuestados consideran que no es así. 
De la pregunta cuatro, se deduce que el $64 \%$ de los encuestados considera que existen muchas formalidades para acceder al Derecho Constitucional de Petición, mientras que el $23 \%$ considera que existen formalidades pero son pocas y el $13 \%$ considera que no existen formalidades para acceder a este derecho constitucional de petición.

De la pregunta cinco, se colige que el $69 \%$ de los encuestados considera que existen muchas formalidades para acceder al Derecho Constitucional de Petición vulnerando el derecho a recibir servicios públicos de calidad, mientras que el $21 \%$ considera que existen pocas formalidades y el $10 \%$ considera que no existen ninguna.

De la pregunta seis, se determina que el $56 \%$ de los encuestados consideran que siempre utilizan el derecho Constitucional de Petición, mientras que el $36 \%$ de los encuestados manifiestan que solamente a veces lo utilizan y solo el $8 \%$ de los encuestados no lo utilizan nunca.

De la pregunta siete, se determina que el $99 \%$ de los encuestados consideran que el derecho de petición debe estar debidamente normado, mientras que el $1 \%$ de los encuestados consideran que no es necesario.

De la pregunta ocho, se colige que el $75 \%$ de los encuestados consideran que procedimiento Oral debe utilizarse en el Derecho de Petición.

De la pregunta nueve, se determina que el $99 \%$ de los encuestados consideran que el derecho de petición se lo puede aplicar por medios electrónicos, mientras que el $1 \%$ de los encuestados consideran que no es necesario.

De la pregunta diez, se deduce que la totalidad de los encuestados consideran que con la elaboración de un anteproyecto de Ley Reformatoria a la Ley Orgánica de Garantías Jurisdiccionales y Control Constitucional se garantizará el derecho de petición, el libre acceso a la información y a recibir servicios públicos de calidad.

\section{DISCUSIÓN}

La investigación brinda como resultado que es indispensable y fundamental una reforma a la Ley Orgánica de Garantías Jurisdiccionales y Control Constitucional para garantizar 
el derecho de petición, el libre acceso a la información y a recibir servicios públicos de calidad, lo cual concuerda con el trabajo de (Serrano de Barrios, 2019), los profesionales del derecho apoyan la utilización de medios electrónicos y el procedimiento oral en el Derecho de Petición, que deben plasmarse en una reforma a la Ley Orgánica de Garantías Jurisdiccionales y Control Constitucional para garantizar el derecho de petición, el libre acceso a la información y a recibir servicios públicos de calidad.

Es por ello, que se redacta un proyecto de ley que busca garantizar el derecho de petición, el libre acceso a la información y a recibir servicios públicos de calidad, ya que la ciudadanía se vería beneficiada con el empleo del procedimiento escrito, oral y cualquier medio electrónico para acceder al derecho constitucional de petición. Si bien la Constitución de la República del Ecuador (2008), se refiere al derecho constitucional de petición no existe un marco legal adecuado que la respalde y que establezca procedimientos claros rápidos y sencillos para acceder a esta garantía constitucional.

Esto produce que se vulneren múltiples derechos constitucionales entre estos el libre acceso a la información y a recibir servicios públicos de calidad, entre otros (Torres, 2017). Es por esta razón, que es sumamente necesario establecer un marco legal y un procedimiento rápido moderno y sencillo para que las instituciones reciban y atiendan nuestras peticiones sin la exigencia de formalidades innecesarias.

\section{CONCLUSIONES}

Si bien la Constitución de la República del Ecuador (2008), establece el Derecho Constitucional de Petición, el legislador no se ha preocupado de Reformar la Ley de Garantías Jurisdiccionales y Control Constitucional para garantizar el ejercicio pleno del derecho constitucional de petición.

El Derecho Constitucional de Petición debe cumplir su función y ser una herramienta que en forma ágil, rápida y sencilla, permita la vinculación de la ciudadanía y la Administración Pública o Privada. 
La aplicación de los métodos y técnicas establecidos en el presente artículo, permitieron extraer los elementos necesarios para construir la propuesta de reforma a la Ley de Garantías Jurisdiccionales y Control Constitucional. Mediante la Ley Reformatoria a la Ley Orgánica de Garantías Jurisdiccionales y Control Constitucional se garantizara el derecho de petición, el libre acceso a la información y a recibir servicios públicos de calidad.

La presente investigación propende normar, rectificar y modernizar la utilización del derecho de Petición en la República del Ecuador, a fin de que las personas naturales y jurídicas, ciudadanía en general puedan solicitar información, presentar quejas, realizar consultas, exigir la prestación de un servicio, etc., en forma directa por medio escrito oral, así como cualquier medio electrónico, eliminando tramites formalidades innecesarias, y de esta manera dar cumplimiento plenamente al Derecho Constitucional de Petición.

\section{ANEXOS}

\section{Proyecto de ley}

\section{Proyecto de Ley Reformatoria a la Ley Orgánica de Garantías Jurisdiccionales y Control Constitucional.}

\section{Objetivo de la Propuesta}

Elaborar un proyecto de Ley Reformatoria a la Ley Orgánica de Garantías Jurisdiccionales y Control Constitucional, con el fin de hacer cumplir el derecho de petición, el libre acceso a la información y a recibir servicios públicos de calidad.

\section{Justificación de la propuesta}

A través de la Ley Reformatoria a la Ley Orgánica de Garantías Jurisdiccionales y Control Constitucional para garantizar el derecho de petición, el libre acceso a la información y a recibir servicios públicos de calidad. Toda la ciudadanía se vería beneficiada con el 
empleo del procedimiento escrito, oral y cualquier medio electrónico para acceder al derecho constitucional de petición. Si bien la Constitución de la República del Ecuador (2008), se refiere al derecho constitucional de petición no existe un marco legal adecuado que la respalde y que establezca procedimientos claros rápidos y sencillos para acceder a esta garantía constitucional. Esto produce que se vulneren múltiples derechos constitucionales entre estos el libre acceso a la información y a recibir servicios públicos de calidad, etc. Es por esta razón, que es sumamente necesario establecer un marco legal y un procedimiento rápido moderno y sencillo para que las instituciones reciban y atiendan nuestras peticiones sin la exigencia de formalidades innecesarias.

\section{Recomendaciones Generales}

La Presidencia de la Republica debe instruir a todos los funcionarios públicos dependientes de la Administración Central y a los funcionarios de todas las instituciones públicas, sin excepción, para que eviten la exigencia de formalidades innecesarias cuando la ciudadanía presente Peticiones.

La Corte Constitucional de la República del Ecuador, debe pronunciarse respecto al Derecho Constitucional de Petición dictando Resoluciones y disposiciones aditivas referentes al Derecho Constitucional de Petición en la Ley Orgánica de Garantías Jurisdiccionales y Control Constitucional.

La Asamblea Nacional del Ecuador, debe tomar en cuenta el Anteproyecto de Ley Reformatoria a la Ley Orgánica de Garantías Jurisdiccionales y Control Constitucional, propuesto en el presente proyecto de Investigación para evitar la vulneración de Derechos Constitucionales, por el vacío legal existente.

\section{REFERENCIAS CONSULTADAS}

1. Ariño Ortiz, G. (2004). Principios de Derecho Público Económico. Lima-Perú: ara.

2. Aldana Zavala, J., \& Isea, J. (2018a). Derechos Humanos y Dignidad Humana. IUSTITIA SOCIALIS, 3(4), 8-23. Recuperado de https://fundacionkoinonia.com.ve/ojs/index.php/lustitia Socialis/article/view/119/1 
$\underline{01}$

3. Aldana Zavala, J., \& Isea Argüelles, J. (2018b). Derechos Humanos y Soberanía. IUSTITIA SOCIALIS, 3(5), 29-48. doi:http://dx.doi.org/10.35381/racji.v3i5.168

4. Asamblea Nacional Constituyente. (1998). Constitución Política de la República del Ecuador. Quito: imprenta nacional.

5. Asamblea Nacional del Ecuador. (2017). Código Orgánico Administrativo. San Francisco de Quito: Lexis.

6. Córdoba Ortega, J. (2013). El Derecho Constitucional de Petición. San José-Costa Rica: Centro de información Jurídica en Línea, Cijul en Línea. Recuperado de https://cijulenlinea.ucr.ac.cr/?submit=Buscar\&s=EL+DERECHO+CONSTITUCIO NAL+DE+PETICION

7. Diario Oficial No. 49.559 de 30 de junio de 2015. Ley 1755 de 2015. Recuperado de http://www.secretariasenado.gov.co/senado/basedoc/ley 1755 2015.html

8. Hernández, R. Fernández, C., y Baptista, P. (2014). Metodología de la investigación. México, Mc Graw Hill Hispanoamericana. Hill Internacional.

9. Pérez Carrillo, J. (2019). La teoría de las fuentes del Derecho. Dimensiones conceptuales y terminológicas. IUSTITIA SOCIALIS, 4(1), 138-150. doi:http://dx.doi.org/10.35381/racji.v4i1.544

10. Serrano de Barrios, N. (2019). La ley de infogobierno en el contexto tecnológico de la gestión pública. IUSTITIA SOCIALIS, 4(7), 201-219. doi:http://dx.doi.org/10.35381/racji.v4i7.395

11. Torres, G. (2017). Visión crítica del acto de administrar justicia. IUSTITIA SOCIALIS, 2(2), 29-44. Recuperado de https://fundacionkoinonia.com.ve/ojs/index.php/lustitia Socialis/article/view/87/72

(C2020 por los autores. Este artículo es de acceso abierto y distribuido según los términos y condiciones de la licencia Creative Commons Atribución-NoComercial-Compartirlgual 4.0 Internacional (CC BY-NC-SA 4.0) (https://creativecommons.org/licenses/by-nc-sa/4.0/). 